\title{
Association between the TRAIL single nucleotide polymorphism rs1131580 and type 2 diabetes mellitus in a Han Chinese population
}

\author{
M.Y. Yu ${ }^{1,2 *}$, P.Q. Zhao ${ }^{1,3 *}$, X.H. Yan ${ }^{4}$, B. Liu ${ }^{1}$, Q.Q. Zhang ${ }^{1}$, R. Wang ${ }^{1}$, \\ C.H. Ma ${ }^{1}$, X.H. Liang ${ }^{1}$, F.L. Zhu ${ }^{1}$ and L.F. Gao ${ }^{1}$ \\ ${ }^{1}$ Key Laboratory for Experimental Teratology of Ministry of Education, \\ Shandong Provincial Key Laboratory of Infection \& Immunology, \\ Institute of Immunology, Shandong University School of Medicine, \\ Shandong, China \\ ${ }^{2}$ Department of Medicine, Binzhou Vocational College, Binzhou, \\ Shandong, China \\ ${ }^{3}$ Department of Clinical Laboratory, Zibo Central Hospital, Zibo, \\ Shandong, China \\ ${ }^{4}$ Shandong Medical College, Linyi, Shandong, China \\ *These authors contributed equally to this study. \\ Corresponding author: L.F. Gao \\ E-mail: glfflg@sdu.edu.cn
}

Genet. Mol. Res. 12 (3): 3455-3464 (2013)

Received January 7, 2013

Accepted May 28, 2013

Published September 10, 2013

DOI http://dx.doi.org/10.4238/2013.September.10.2

\begin{abstract}
Tumor necrosis factor (TNF)-related apoptosis-inducing ligand (TRAIL) is expressed in different tissues and cells, including the pancreas and lymphocytes, and it can selectively induce apoptosis in tumor cells but not in most normal cells. TRAIL plays critical roles in type 1 diabetes mellitus, and is involved in type 2 diabetes mellitus (T2DM). We recently discovered the association of nonalcoholic fatty liver disease, a risk factor for T2DM, with a single nucleotide polymorphism (SNP) in the TRAIL (TNFSF10) gene at site 1595C/T (rs1131580), indicating the possible association of T2DM with this TRAIL polymorphism. The aim of this study was to investigate the
\end{abstract}


relationship of the TRAIL SNP at site 1595C/T (rs1131580) with T2DM susceptibility and the biometabolic parameters of T2DM in a Han Chinese population. The polymerase chain reaction-restriction fragment length polymorphism method was used to genotype SNP rs1131580 in 292 patients with T2DM and 266 healthy controls. We found that the frequency of the CC genotype and that of the C allele of rs 1131580 were significantly higher in T2DM patients than in the control group. Additionally, the triglyceride and serum creatinine levels of T2DM patients with the CC genotype were significantly higher than those of patients with the TT genotype. Thus, the CC genotype of the TRAIL SNP at $1595 \mathrm{C} / \mathrm{T}$ (rs1131580) confers increased susceptible to T2DM in a Han Chinese population from Shandong Province. These data suggest that the CC genotype at this SNP is related to diabetic severity and it might be a candidate for the prognostic assessment of T2DM.

Key words: Tumor necrosis factor-related apoptosis-inducing ligand; Polymerase chain reaction-restriction fragment length polymorphism; Type 2 diabetes mellitus; Single nucleotide polymorphism

\section{INTRODUCTION}

Diabetes mellitus affects about 150 million people worldwide. The 2 most common forms of diabetes are type 1 diabetes mellitus (T1DM) and type 2 diabetes mellitus (T2DM). T2DM is the most common form of diabetes, accounting for 90 to $95 \%$ of all cases of diabetes worldwide (Zimmet et al., 2001). At present, T2DM is one of the most challenging health-care problems. The prevalence of T2DM has been increasing dramatically worldwide. China has the highest prevalence of diabetes in the world, and the incidence of diabetes is increasing rapidly, especially in urban areas (Villegas et al., 2006). Many factors, including obesity, hypertension, elevated cholesterol, and metabolic syndrome, increase the risk of developing T2DM. There is also a strong inheritable genetic component in T2DM (Freeman and Cox, 2006). T2DM is a chronic disease caused by the aberrant expression of many genes such as TNF- $\alpha$, $T G F-\beta$, and $I L-1$ (Wachlin et al., 2003; Hanley et al., 2006; Lin et al., 2009). In addition, it has been reported that hyperglycemic conditions induce the expression of apoptosis-regulatory genes by the renal tubular epithelium (Ortiz et al., 1997). Apoptosis can also be detected in renal biopsy samples from diabetic patients, suggesting a role for apoptosis-regulatory genes in diabetic pathogenesis (Kumar et al., 2004).

Tumor necrosis factor (TNF)-related apoptosis-inducing ligand (TRAIL), also known as Apo-2L, is a new member of the TNF superfamily. TRAIL was first identified by Wiley et al. (1995). TRAIL is expressed in different tissues and cells, including the pancreas and lymphocytes, and can selectively induce the apoptosis of tumor cells but not that of most normal cells. However, TRAIL is involved not only in apoptosis and immune regulation but also in vascular biology (Kavurma et al., 2008). Recently, TRAIL was suggested to be a potential new player in the pathogenesis of diabetes. TRAIL has been associated with both T1DM and T2DM (Corallini et al., 2007). However, TRAIL plays a dual role in diabetes depending on the type and the stage of the disease (Vaccarezza et al., 2007). Emerging evidence shows that TRAIL 
plays critical roles in T1DM. TRAIL deficiency accelerates the development of autoimmune diabetes, while treatment with recombinant TRAIL ameliorates the severity of streptozotocininduced T1DM (Lamhamedi-Cherradi et al., 2003; Zauli et al., 2010). In T2DM patients, the serum levels of TRAIL showed a tendency to decrease after insulin treatment, suggesting that TRAIL might be involved in diabetic vascular abnormalities by acting as an endogenous regulator of the vascular tone (Corallini et al., 2007). However, an association between single nucleotide polymorphisms (SNPs) in TRAIL (TNFSF10) and T2DM has not been reported. We previously found that the TT genotype of TRAIL at nucleotide 1595 was associated with a lower risk of fatty liver disease (FLD), which is related to the development and progression of T2DM (Yan et al., 2009). The aim of the current study was to evaluate the relationship of variants at nucleotide 1595 (rs1131580) in TRAIL to T2DM susceptibility and to biometabolic parameters in T2DM patients.

\section{MATERIAL AND METHODS}

\section{Subjects}

Two hundred and ninety-two patients with T2DM that fulfilled the new diabetes diagnostic criteria issued by the American Diabetes Association in 1997 and 266 healthy controls were recruited at the Shandong University affiliated Qilu Hospital and Zibo Central Hospital from January 2007 to January 2012. T2DM patients and healthy controls were from Shandong Province and all subjects were all ethnically Han. All recruited healthy controls were excluded from having autoimmune diseases. There were no significant differences in age or gender ratios between the 2 groups. This study was approved by the Medical Ethics Committee of Shandong University, and informed consent was obtained from all subjects before the study. The characteristics of the subjects are summarized in Table 1.

\begin{tabular}{lcc} 
Table 1. Characteristics of type 2 diabetes mellitus (T2DM) patients and control subjects. \\
\hline Subjects & T2DM $(\mathrm{N}=292)$ & Normal $(\mathrm{N}=266)$ \\
\hline Age mean (years) & $55.73 \pm 8.54$ & $53.73 \pm 8.74$ \\
Gender (male/female) & $156 / 136$ & $139 / 127$ \\
Race & Chinese & Chinese \\
SBP $(\mathrm{mmHg})$ & $131.39 \pm 12.62$ & - \\
DBP $(\mathrm{mmHg})$ & $84.03 \pm 7.92$ & - \\
TC $(\mathrm{mM})$ & $4.64 \pm 1.21$ & - \\
HDL $(\mathrm{mM})$ & $2.14 \pm 1.02$ & - \\
LDL $(\mathrm{mM})$ & $3.02 \pm 0.84$ & - \\
FPG $(\mathrm{mM})$ & $8.96 \pm 2.55$ & - \\
GHbAlc $(\%)$ & $8.43 \pm 1.99$ & - \\
TG $(\mathrm{mM})$ & $2.42 \pm 1.46$ & - \\
BUN $(\mathrm{mM})$ & $5.02 \pm 2.83$ & - \\
SCr $(\mu \mathrm{M})$ & $81.42 \pm 40.11$ & - \\
\hline
\end{tabular}

Values are reported means $\pm \mathrm{SD}$ or $\mathrm{N}$, unless otherwise stated. $\mathrm{SBP}=$ systolic blood pressure; $\mathrm{DBP}=$ diastolic blood pressure; $\mathrm{TC}=$ total cholesterol; $\mathrm{HDL}=$ high-density lipoprotein; $\mathrm{LDL}=$ low-density lipoprotein; $\mathrm{FPG}=$ fasting plasma glucose; $\mathrm{GHbA1c}=$ glycated hemoglobin $\mathrm{A} 1 \mathrm{c} ; \mathrm{TG}=$ triglyceride; $\mathrm{BUN}=$ blood urea nitrogen; $\mathrm{SCr}=$ serum creatinine.

\section{Detection of biometabolic parameters}

Serum was separated following standard protocols and prepared for the detection 
of biometabolic parameters. Briefly, we left the whole blood for $1 \mathrm{~h}$ at $37^{\circ} \mathrm{C}$ to allow it to clot, then centrifuged at $4000 \mathrm{rpm}$ for $20 \mathrm{~min}$ at $4^{\circ} \mathrm{C}$. The serum was collected and stored at $-20^{\circ} \mathrm{C}$. Biometabolic parameters including triglyceride (TG), high-density lipoprotein (HDL), low-density lipoprotein (LDL), glycated hemoglobin A1c (GHbA1c), fasting plasma glucose (FPG), total cholesterol (TC), blood urea nitrogen (BUN), and serum creatinine ( $\mathrm{SCr}$ ) were detected in the sera of T2DM patients using conventional methods with a Beckman Coulter Automatic Biochemical Analyzer (USA) (Yang et al., 2012).

\section{DNA extraction}

Blood treated with anticoagulant was preserved at $-20^{\circ} \mathrm{C}$ for genomic DNA extraction. Genomic DNA was extracted from whole blood using a leukocyte genomic DNA isolation kit (TIANGEN Bio-Engineering Co. Ltd., China) according to manufacturer instructions. The genomic DNA obtained was stored at $-20^{\circ} \mathrm{C}$ for SNP analysis.

\section{TRAIL genotyping}

Polymerase chain reaction-restriction fragment length polymorphism (PCR-RFLP) was used for SNP genotyping. Specific primers were designed based on the TRAIL gene sequence and a previously published study (Gray et al., 2001). PCR was performed in a final volume of $25 \mu \mathrm{L}$ with $100 \mathrm{ng}$ DNA template, $2.5 \mu \mathrm{L} 10 \mathrm{X}$ PCR buffer, $0.5 \mu \mathrm{L}$ dNTPs, $10 \mathrm{pM}$ forward primer (5'-aacatcttctgtctttataatc-3') and reverse primer (5'-aaataacacgtacttactgaag-3'), and 1.25 U Taq-DNA-polymerase (Takara, Japan). PCR cycling conditions were as follows: $94^{\circ} \mathrm{C}$ for $5 \mathrm{~min}$, followed by 30 cycles of $94^{\circ} \mathrm{C}$ for $45 \mathrm{~s}, 48^{\circ} \mathrm{C}$ for $45 \mathrm{~s}$, and $72^{\circ} \mathrm{C}$ for $45 \mathrm{~s}$, with a final extension step at $72^{\circ} \mathrm{C}$ for $5 \mathrm{~min}$. PCR products were digested with Tas I at $65^{\circ} \mathrm{C}$ for 3 $\mathrm{h}$. The digested products were checked by electrophoresis on $2.5 \%$ agarose gels and visualized by staining with ethidium bromide. The desired genotypes of TRAIL were confirmed by DNA sequencing in 2 randomly selected samples.

\section{Statistical analysis}

All data are reported as means $\pm \mathrm{SD}$. The genotype and allele frequencies were calculated manually and were found to follow Hardy-Weinberg equilibrium in both groups. The differences in genotype and allele frequencies between the 2 groups were analyzed by the chi-square test and the Fisher exact test, respectively. General linear regression analyses were used to calculate differences in quantitative traits among T2DM patients with different TRAIL genotypes and P values shown were adjusted for age and gender applying an additive genetic model. All data were analyzed with the GraphPad Prism 5.0 software (GraphPad Software, Inc., San Diego, CA, USA). A two-sided $\mathrm{P}$ value less than 0.05 was considered to indicate statistical significance.

\section{RESULTS}

\section{Genotyping of the rs1131580 SNP in TRAIL}

Consistent with our previous studies, 3 genotypes were identified at site 1595 in 
TRAIL in all recruited subjects. Amplified PCR products were cut into 291- and 193-bp fragments (genotype CC) or 291-, 193-, 131-, and 62-bp fragments (genotype CT), or 291-, 131-, and 62-bp fragments (genotype TT) after digestion with TasI (Figure 1A). Each genotype was verified by DNA sequencing (Figure 1B).

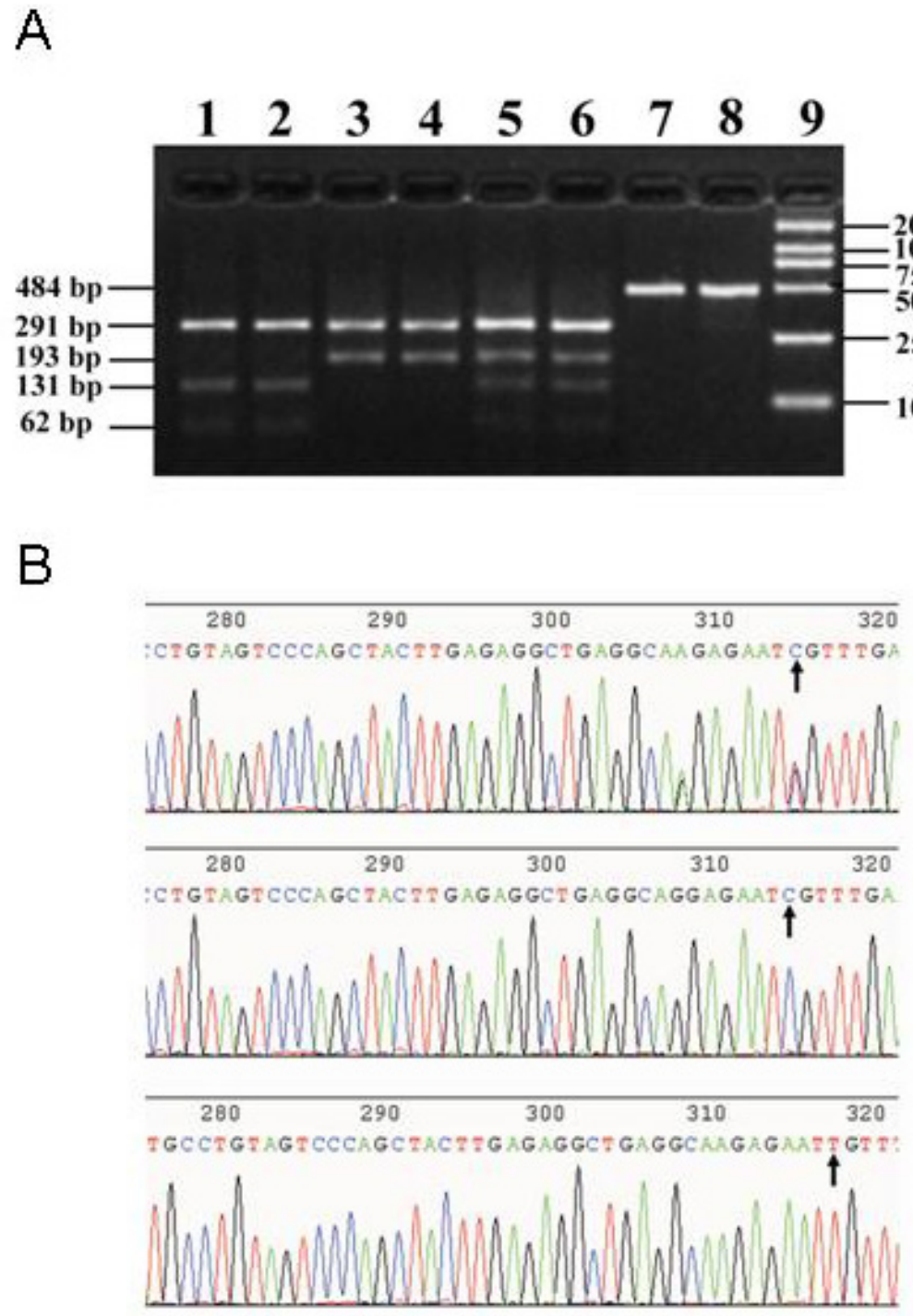

Figure 1. Genotyping of the TRAIL gene at site 1595 (rs1131580). PCR products and digestion products were electrophoretically separated on a $2.5 \%$ agarose gel and stained with ethidium bromide. Each genotype of TRAIL was verified by DNA sequencing. A. PCR products and restriction enzyme digestion by TasI in the 3'-UTR at position 1595. Lanes 1 and 2 =TT genotype with 291-, 131- and 62-bp fragments; lanes 3 and $4=$ CC genotype with 291- and 193-bp fragments; lanes 5 and $6=$ CT genotype with 291-, 193-, 131- and 62-bp fragments; lanes 7 and $8=$ PCR products; lane 9 = DL2 000 DNA marker. B. DNA sequencing of PCR products with the CT genotype (top panel), CC genotype (middle panel), or TT genotype (bottom panel) in the 3'-UTR at position 1595 (shown by arrows). 


\section{Genotype and allele frequencies of rs1131580 in T2DM patients and healthy controls}

Based on the electrophoresis results, we determined and recorded the genotype of each individual and calculated the genotype and allele frequencies of this SNP manually. Genotype and allele frequencies of the SNP in the 2 groups were in Hardy-Weinberg equilibrium (control group: $\chi^{2}=1.7991, \mathrm{P}=0.4068$; T2DM group: $\left.\chi^{2}=0.0078, \mathrm{P}=0.9961\right)$. The frequency of the CC genotype was significantly higher in T2DM subjects than in healthy controls (T2DM group vs control group: $32.19 v s 25.94 \%, \mathrm{P}<0.05)$. Consistent with this result, the frequency of the C allele of SNP rs1131580 was significantly higher in the T2DM group than in the control group [T2DM group $v s$ control group: 56.85 vs $48.87 \%, \mathrm{P}<0.01$, OR $=1.378,95 \%$ confidence interval $(\mathrm{CI})=1.088-1.745]($ Table 2$)$.

\begin{tabular}{|c|c|c|c|c|c|c|c|c|}
\hline \multirow[t]{2}{*}{ Group } & \multirow[t]{2}{*}{$\mathrm{N}$} & \multicolumn{3}{|c|}{${\text { Genotype frequency }{ }^{\mathrm{a}}, \mathrm{N}(\%)}$} & \multirow[t]{2}{*}{$P$} & \multicolumn{2}{|c|}{ Allele frequency ${ }^{\mathrm{b}}, \mathrm{N}(\%)$} & \multirow[t]{2}{*}{$P$} \\
\hline & & $\mathrm{CC}$ & CT & TT & & $\mathrm{C}$ & $\mathrm{T}$ & \\
\hline T2DM & 292 & $94(32.19 \%)$ & $144(49.32 \%)$ & $54(18.49 \%)$ & 0.0195 & $332(56.85 \%)$ & $252(43.15 \%)$ & 0.0083 \\
\hline Control & 266 & $69(25.94 \%)$ & $122(45.86 \%)$ & $75(27.82 \%)$ & & $260(48.87 \%)$ & $272(51.13 \%)$ & \\
\hline
\end{tabular}

${ }^{\mathrm{a}} \mathrm{T} 2 \mathrm{DM}$ group $v s$ control group, $\mathrm{P}<0.05 ;{ }^{\mathrm{b}} \mathrm{T} 2 \mathrm{DM}$ group $v s$ control group, $\mathrm{P}<0.01, \mathrm{OR}=1.378,95 \% \mathrm{CI}=1.088-1.745$.

\section{Levels of biometabolic parameters in T2DM patients with different TRAIL genotypes}

T2DM patients were classified into 3 groups according to their genotypes (CC, CT, or TT) at site 1595 in TRAIL, and the levels of biometabolic parameters in these groups were analyzed. The results indicated that the levels of TG and SCr in T2DM patients with genotype CC (TG: $2.57 \pm 1.88 \mathrm{mM}$; SCr: $91.11 \pm 64.45 \mu \mathrm{M}$ ) were significantly higher than those of T2DM patients with genotype TT (TG: $1.74 \pm 0.86 \mathrm{mM}$; SCr: $76.16 \pm 20.61 \mu \mathrm{M}$ ). Although FPG levels in T2DM patients with the CC genotype $(8.40 \pm 2.51 \mathrm{mM})$ were significantly lower than those of patients with the CT genotype $(9.32 \pm 2.54 \mathrm{mM})$, no differences in FPG levels were found between patients with the $\mathrm{CC}(8.40 \pm 2.51 \mathrm{mM})$ and TT genotypes $(8.98 \pm 2.52 \mathrm{mM})$. TC, HDL, LDL, GHbA1c, and BUN showed no significant differences in T2DM patients with different TRAIL genotypes (Table 3).

\begin{tabular}{|c|c|c|c|c|}
\hline Items & $\mathrm{CC}(\mathrm{N}=94)$ & $\mathrm{CT}(\mathrm{N}=144)$ & TT $(\mathrm{N}=54)$ & $P$ \\
\hline $\mathrm{TC}(\mathrm{mM})$ & $4.65 \pm 1.08$ & $4.60 \pm 1.33$ & $4.73 \pm 1.10$ & 0.7761 \\
\hline $\mathrm{HDL}(\mathrm{mM})$ & $2.05 \pm 1.04$ & $2.24 \pm 1.01$ & $2.01 \pm 0.99$ & 0.0899 \\
\hline LDL(mM) & $3.03 \pm 0.85$ & $3.00 \pm 0.85$ & $3.07 \pm 0.82$ & 0.8580 \\
\hline FPG (mM) & $8.40 \pm 2.51$ & $9.32 \pm 2.54$ & $8.98 \pm 2.52$ & $0.0227^{\star}$ \\
\hline GHbA1c (\%) & $8.19 \pm 2.10$ & $8.60 \pm 2.01$ & $8.41 \pm 1.70$ & 0.2800 \\
\hline $\mathrm{TG}(\mathrm{mM})$ & $2.57 \pm 1.88$ & $2.57 \pm 1.25$ & $1.74 \pm 0.86$ & $0.0006^{\mathbf{A}}$ \\
\hline BUN(mM) & $5.49 \pm 4.50$ & $4.85 \pm 1.52$ & $4.65 \pm 1.26$ & 0.1233 \\
\hline $\mathrm{SCr}(\mu \mathrm{M})$ & $91.11 \pm 64.45$ & $77.06 \pm 18.00$ & $76.16 \pm 20.61$ & $0.0166^{\mathbf{\Delta}}$ \\
\hline
\end{tabular}

$\mathbf{A}<0.05$. For abbreviations, see legend to Table 1 . 


\section{DISCUSSION}

T2DM is a complex polygenic disease influenced by environmental and genetic factors. Over 30 T2DM susceptibility loci with different effect sizes have been identified and replicated by genetic association studies, and several genome-wide association scans for T2DM have also been carried out recently (Sladek et al., 2007; Unoki et al., 2008; Rung et al., 2009; Langberg et al., 2012). It has been reported that a functional polymorphism in the $T N F-\alpha$ gene, a long-standing T2DM candidate gene, is associated with T2DM and that a genetic polymorphism in the TNF- $\alpha$ promoter at site $-308 \mathrm{G} / \mathrm{A}$ is associated with diabetes and T2DM in the elderly (Chui et al., 2007; Susa S et al., 2008). However, emerging evidence from large-scale association analyses shows that the majority of common variation in the TNF/LTA gene region is not related to T2DM (Zeggini et al., 2005; Boraska et al., 2010). Plasma fatty acid concentration and distribution are closely linked to the development and progression of T2DM. SNPs in the TNF superfamily member $10 b$ (TNFRSF10B) gene, which encodes a receptor for TRAIL, appear to play a key role in fatty acid metabolism, suggesting a correlation between TNFRSF 10B functional variants and T2DM risk (Voruganti et al., 2010). However, the relationship of TRAIL, a new member of the TNF superfamily, with T2DM remains unclear.

There are several SNPs in TRAIL, including 4 SNPs in the 5'-regulatory region, 2 SNPs within exons, and 5 SNPs in the 3'-untranslated region (3'-UTR) (Unoki et al., 2000; Wang et al., 2000; Gray et al., 2001). Generally, 3'-UTR has wide-range influences on gene regulation (Zhang et al., 2004; Watanabe et al., 2007). The polymorphism at position 1595 of TRAIL (rs1131580) was found to be associated with multiple sclerosis susceptibility in Japanese patients (Kikuchi et al., 2005). We also found that the TT genotype at nucleotide 1595 in TRAIL engendered a lower risk of FLD and a less severe form of steatosis in FLD patients in a Chinese population (Yan et al., 2009). Recently, the TRAIL SNP rs1131532 was identified as a possible prognostic factor for survival in patients operated on for invasive breast cancer (Jung et al., 2010). In addition, a promoter SNP in TRAIL was shown to functionally modulate the role of TRAIL in breast cancer pathogenesis (Pal et al., 2011). We also evaluated 4 SNPs in the promoter region of TRAIL. However, no SNPs were identified in a Chinese population at sites $-707,-665,-597$ of TRAIL, and genotype and allele frequencies at -621 showed no significant differences between non-alcoholic or alcoholic FLD patients and healthy controls. Since the 3'-UTR may be involved in gene regulation, the variant of TRAIL at site 1595 (rs1131580) likely influences TRAIL gene expression by changing a potential microRNA binding sequence, suggesting that it is a functional mutant. In our previous study, we found that SNP rs 1131580 in TRAIL was correlated with FLD susceptibility in a Han Chinese population. Therefore, we selected this 3'-UTR SNP for our current study.

Our results in this study are consistent with those of our previous report in that 3 genotypes were found at site 1595 in TRAIL in the study subjects (Yan et al., 2009). In the present study, we found that the CC and CT genotypes at rs 1131580 were more commonly found in T2DM patients than the TT genotype. The frequency of the CC genotype was also significantly higher in the T2DM group than in the control group as was the frequency of the $\mathrm{C}$ allele, suggesting that the CC genotype at rs1131580 might confer susceptibility to T2DM together with other risk factors. This result is consistent with the fact that nonalcoholic fatty liver disease is a risk factor for T2DM (Fan et al., 2007; Arase et al., 2009). Consistent with our previous study on fatty liver diseases, TG levels in T2DM patients with the CC genotype were significantly 
higher than those of patients with the TT genotype. Since TG is an independent risk factor for many T2DM-associated complications and coexisting liver diseases are a risk factor for the development of T2DM (Wanner and Krane, 2011), the CC genotype of site 1595 in TRAIL might be associated with the severity of diabetes. However, the role of TRAIL in T2DM has not been investigated so far. Serum TRAIL levels were associated with carotid intima-media thickness in a subset of T2DM patients with macrovascular diseases (Kawano et al., 2011). In addition, the serum concentrations of TRAIL and osteoprotegerin, the endogenous decoy receptor of TRAIL, in T2DM patients with microalbuminuria and macroalbuminuria are significantly higher than those of patients with normoalbuminuria, and serum osteoprotegerin was identified to be an independent factor associated with the severity of diabetic nephropathy (Chang et al., 2011). In this study, we also detected higher levels of Scr in T2DM patients with the CC genotype, further indicating that patients with the CC genotype at SNP rs1131580 of TRAIL might have more severe T2DM than patients with the TT genotype.

In summary, our results demonstrate that genotype CC at site 1595 of the TRAIL gene engenders a higher risk for T2DM and a more severe form of T2DM. We speculate that this potentially functional polymorphism in the TRAIL gene might be a good candidate for T2DM diagnosis and prognosis. However, further studies are needed to analyze the association of TRAIL polymorphisms with other aspects of T2DM, such as insulin resistance and $\beta$ cell dysfunction, to clarify the role of the TRAIL polymorphism rs 1131580 in T2DM pathogenesis. Additionally, due to the sample size of this study, a large-scale association analysis of TRAIL gene functional variants and T2DM risk is necessary to validate these results.

\section{Conflicts of interest}

We declare no conflict of interests.

\section{ACKNOWLEDGEMENTS}

Research supported in part by grants from the National Nature Science Foundation of China (\#30872298, \#81172862, and \#81100203) and the Shandong Provincial Natural Science Foundation (\#ZR2010HM025). We would like to thank Dr. Qiji Liu for suggestions and Dr. Xiubin Sun for data analysis.

\section{REFERENCES}

Arase Y, Suzuki F, Ikeda K, Kumada H, et al. (2009). Multivariate analysis of risk factors for the development of type 2 diabetes in nonalcoholic fatty liver disease. J. Gastroenterol. 44: 1064-1070.

Boraska V, Rayner NW, Groves CJ, Frayling TM, et al. (2010). Large-scale association analysis of TNF/LTA gene region polymorphisms in type 2 diabetes. BMC Med. Genet. 11: 69.

Chang YH, Lin KD, He SR, Hsieh MC, et al. (2011). Serum osteoprotegerin and tumor necrosis factor related apoptosis inducing-ligand (TRAIL) are elevated in type 2 diabetic patients with albuminuria and serum osteoprotegerin is independently associated with the severity of diabetic nephropathy. Metabolism 60: 1064-1069.

Chui MH, Papanikolaou Y, Fontaine-Bisson B, Turcotte J, et al. (2007). The TNF-alpha-238G > a single-nucleotide polymorphism protects against memory decline in older adults with type 2 diabetes. Behav. Neurosci. 121: 619-624.

Corallini F, Celeghini C, Rizzardi C, Pandolfi A, et al. (2007). Insulin down-regulates TRAIL expression in vascular smooth muscle cells both in vivo and in vitro. J. Cell Physiol. 212: 89-95.

Fan JG, Li F, Cai XB, Peng YD, et al. (2007). Effects of nonalcoholic fatty liver disease on the development of metabolic 
disorders. J. Gastroenterol. Hepatol. 22: 1086-1091.

Freeman H and Cox RD (2006). Type-2 diabetes: a cocktail of genetic discovery. Hum. Mol. Genet. 15 Spec No 2: R202-R209.

Gray HL, Sorensen EL, Hunt JS and Ober C (2001). Three polymorphisms in the 3' UTR of the TRAIL (TNF-related apoptosis-inducing ligand) gene. Genes Immun. 2: 469-470.

Hanley S, Liu S, Lipsett M, Castellarin M, et al. (2006). Tumor necrosis factor-alpha production by human islets leads to postisolation cell death. Transplantation 82: 813-818.

Jung JH, Chae YS, Moon JH, Kang BW, et al. (2010). TNF superfamily gene polymorphism as prognostic factor in early breast cancer. J. Cancer Res. Clin. Oncol. 136: 685-694.

Kavurma MM, Schoppet M, Bobryshev YV, Khachigian LM, et al. (2008). TRAIL stimulates proliferation of vascular smooth muscle cells via activation of NF-kappaB and induction of insulin-like growth factor-1 receptor. J. Biol. Chem. 283: 7754-7762.

Kawano N, Mori K, Emoto M, Lee E, et al. (2011). Association of serum TRAIL levels with atherosclerosis in patients with type 2 diabetes mellitus. Diabetes Res. Clin. Pract. 91: 316-320.

Kikuchi S, Miyagishi R, Fukazawa T, Yabe I, et al. (2005). TNF-related apoptosis inducing ligand (TRAIL) gene polymorphism in Japanese patients with multiple sclerosis. J. Neuroimmunol. 167: 170-174.

Kumar D, Robertson S and Burns KD (2004). Evidence of apoptosis in human diabetic kidney. Mol. Cell Biochem. 259: 67-70.

Lamhamedi-Cherradi SE, Zheng S, Tisch RM and Chen YH (2003). Critical roles of tumor necrosis factor-related apoptosis-inducing ligand in type 1 diabetes. Diabetes 52: 2274-2278.

Langberg KA, Ma L, Sharma NK, Hanis CL, et al. (2012). Single nucleotide polymorphisms in JAZF1 and BCL11A gene are nominally associated with type 2 diabetes in African-American families from the GENNID study. J. Hum. Genet. 57: 57-61.

Lin HM, Lee JH, Yadav H, Kamaraju AK, et al. (2009). Transforming growth factor-beta/Smad3 signaling regulates insulin gene transcription and pancreatic islet beta-cell function. J. Biol. Chem. 284: 12246-12257.

Ortiz A, Ziyadeh FN and Neilson EG (1997). Expression of apoptosis-regulatory genes in renal proximal tubular epithelial cells exposed to high ambient glucose and in diabetic kidneys. J. Investig. Med. 45: 50-56.

Pal R, Gochhait S, Chattopadhyay S, Gupta P, et al. (2011). Functional implication of TRAIL -716 C/T promoter polymorphism on its in vitro and in vivo expression and the susceptibility to sporadic breast tumor. Breast Cancer Res. Treat. 126: 333-343.

Rung J, Cauchi S, Albrechtsen A, Shen L, et al. (2009). Genetic variant near IRS1 is associated with type 2 diabetes, insulin resistance and hyperinsulinemia. Nat. Genet. 41: 1110-1115.

Sladek R, Rocheleau G, Rung J, Dina C, et al. (2007). A genome-wide association study identifies novel risk loci for type 2 diabetes. Nature 445: 881-885.

Susa S, Daimon M, Sakabe J, Sato H, et al. (2008). A functional polymorphism of the TNF-alpha gene that is associated with type 2 DM. Biochem. Biophys. Res. Commun. 369: 943-947.

Unoki H, Takahashi A, Kawaguchi T, Hara K, et al. (2008). SNPs in KCNQ1 are associated with susceptibility to type 2 diabetes in East Asian and European populations. Nat. Genet. 40: 1098-1102.

Unoki M, Furuta S, Onouchi Y, Watanabe O, et al. (2000). Association studies of 33 single nucleotide polymorphisms (SNPs) in 29 candidate genes for bronchial asthma: positive association a T924C polymorphism in the thromboxane A2 receptor gene. Hum. Genet. 106: 440-446.

Vaccarezza M, Delbello G and Zauli G (2007). A role of the TRAIL-TRAIL receptor system in the pathogenesis of diabetes. Acta Biomed. 78 (Suppl 1): 262-267.

Villegas R, Shu XO, Li H, Yang G, et al. (2006). Physical activity and the incidence of type 2 diabetes in the Shanghai women's health study. Int. J. Epidemiol. 35: 1553-1562.

Voruganti VS, Cole SA, Ebbesson SO, Goring HH, et al. (2010). Genetic variation in APOJ, LPL, and TNFRSF10B affects plasma fatty acid distribution in Alaskan Eskimos. Am. J. Clin. Nutr. 91: 1574-1583.

Wachlin G, Augstein P, Schroder D, Kuttler B, et al. (2003). IL-1beta, IFN-gamma and TNF-alpha increase vulnerability of pancreatic beta cells to autoimmune destruction. J. Autoimmun. 20: 303-312.

Wang Q, Ji Y, Wang X and Evers BM (2000). Isolation and molecular characterization of the 5'-upstream region of the human TRAIL gene. Biochem. Biophys. Res. Commun. 276: 466-471.

Wanner C and Krane V (2011). Recent advances in the treatment of atherogenic dyslipidemia in type 2 diabetes mellitus. Kidney Blood Press Res. 34: 209-217.

Watanabe S, Takeshige K and Muta T (2007). A cis-element in the 3'-untranslated region of IkappaB-zeta mRNA governs its stimulus-specific expression. Biochem. Biophys. Res. Commun. 356: 785-791.

Wiley SR, Schooley K, Smolak PJ, Din WS, et al. (1995). Identification and characterization of a new member of the TNF 
family that induces apoptosis. Immunity 3: 673-682.

Yan X, Xu L, Qi J, Liang X, et al. (2009). sTRAIL levels and TRAIL gene polymorphisms in Chinese patients with fatty liver disease. Immunogenetics 61: 551-556.

Yang HL, Kong L, Hou LL, Shen HF, et al. (2012). Analysis of risk factors for polypoid lesions of gallbladder among health examinees. World J. Gastroenterol. 18: 3015-3019.

Zauli G, Toffoli B, di Iasio MG, Celeghini C, et al. (2010). Treatment with recombinant tumor necrosis factor-related apoptosis-inducing ligand alleviates the severity of streptozotocin-induced diabetes. Diabetes 59: 1261-1265.

Zeggini E, Groves CJ, Parkinson JR, Halford S, et al. (2005). Large-scale studies of the association between variation at the TNF/LTA locus and susceptibility to type 2 diabetes. Diabetologia 48: 2013-2017.

Zhang XY, Zhang XD, Borrow JM, Nguyen T, et al. (2004). Translational control of tumor necrosis factor-related apoptosis-inducing ligand death receptor expression in melanoma cells. J. Biol. Chem. 279: 10606-10614.

Zimmet P, Alberti KG and Shaw J (2001). Global and societal implications of the diabetes epidemic. Nature 414: 782-787. 